\title{
Snow instability evaluation: calculating the skier-induced stress in a multi-layered snowpack
}

\author{
Fabiano Monti $^{1,2, *}$, Johan Gaume ${ }^{1, *}$, Alec van Herwijnen ${ }^{1}$, and Jürg Schweizer ${ }^{1}$ \\ ${ }^{1}$ WSL Institute for Snow and Avalanche Research SLF, Davos, Switzerland \\ ${ }^{2}$ ALPsolut S. r. 1., Via Saroch 1098b, c/o Plaza Placheda, 23030 Livigno, Italy \\ * These two authors equally contributed to this work \\ Correspondence to: Johan Gaume (johan.gaume@ gmail.com)
}

Received: 23 June 2015 - Published in Nat. Hazards Earth Syst. Sci. Discuss.: 14 August 2015

Revised: 22 February 2016 - Accepted: 2 March 2016 - Published: 18 March 2016

\begin{abstract}
The process of dry-snow slab avalanche formation can be divided into two phases: failure initiation and crack propagation. Several approaches tried to quantify slab avalanche release probability in terms of failure initiation based on shear stress and strength. Though it is known that both the properties of the weak layer and the slab play a major role in avalanche release, most previous approaches only considered slab properties in terms of slab depth, average density and skier penetration. For example, for the skier stability index, the additional stress (e.g. due to a skier) at the depth of the weak layer is calculated by assuming that the snow cover can be considered a semi-infinite, elastic, half-space. We suggest a new approach based on a simplification of the multi-layered elasticity theory in order to easily compute the additional stress due to a skier at the depth of the weak layer, taking into account the layering of the snow slab and the substratum. We first tested the proposed approach on simplified snow profiles, then on manually observed snow profiles including a stability test and, finally, on simulated snow profiles. Our simple approach reproduced the additional stress obtained by finite element simulations for the simplified profiles well - except that the sequence of layering in the slab cannot be replicated. Once implemented into the classical skier stability index and applied to manually observed snow profiles classified into different stability classes, the classification accuracy improved with the new approach. Finally, we implemented the refined skier stability index into the $1-\mathrm{D}$ snow cover model SNOWPACK. The two study cases presented in this paper showed promising results even though further verification is still needed. In the future, we intend to implement the proposed approach for
\end{abstract}

describing skier-induced stress within a multi-layered snowpack into more complex models which take into account not only failure initiation but also crack propagation.

\section{Introduction}

The prediction of snow avalanches in mountainous terrain is very challenging due to the partly stochastic nature of some of the meteorological processes acting on the snow cover. It is currently not possible to predict the exact timing and location of a dry-snow slab avalanche (Schweizer et al., 2003a). Avalanche forecasters use and interpret, among other things, field data to estimate the degree of avalanche danger. These data may be ranked according to their relevance (entropy) with respect to estimating instability (McClung, 2002). Stability tests are recognized to provide the most valuable snow stability information, second only to the direct observation of instabilities (LaChapelle, 1980). However, data interpretation is crucial for assessing snow instability (Schweizer and Wiesinger, 2001), and though several methods have been developed to quantify this process, it is still lacking objectivity (e.g. Schweizer et al., 2008b).

The physical and mechanical processes of dry-snow slab avalanche release can be grouped into two distinct and subsequent phases: failure initiation and crack propagation (Schweizer et al., 2003a). In most avalanche accidents, the victims themselves, or another member of their group, triggered the fatal avalanche (Schweizer and Lütschg, 2001; Jamieson et al., 2010). Hence, the factors contributing to the failure of the snowpack caused by a skier (or any other over- 
snow traveller) are of major importance and need to be considered adequately.

Several approaches tried to quantify the slab avalanche release probability in terms of failure initiation, based on a stress-strength approach, such as skier stability index (Föhn, 1987b; Jamieson and Johnston, 1998), or fracture mechanics approaches assuming the presence of a weak spot (or a crack) within the weak layer (McClung, 1979; Heierli and Zaiser, 2007; Heierli et al., 2008; Chiaia et al., 2008; Gaume et al., 2013, 2014, 2015a, b). Both weak layer and slab play a crucial role in avalanche release (McClung and Schweizer, 1999). In general, only the slab depth and its average density were considered within the above-mentioned approaches for quantifying the amount of stress reaching the weak layer (Föhn, 1987b). However, the multi-layer character of the snowpack, generally not taken into account, plays a significant role not only in the failure initiation process (Habermann et al., 2008) but also in crack propagation (Heierli and Zaiser, 2007; Sigrist and Schweizer, 2007; van Herwijnen and Jamieson, 2007; Schweizer et al., 2011). Indeed, the layered character of the snow cover determines the amount of stress at the depth of the weak layer (Schweizer, 1993; Habermann et al., 2008). In particular, slab hardness influences the stress distribution below a skier, e.g. low values are found below hard slabs (Schweizer et al., 1995; Camponovo and Schweizer, 1997; Schweizer and Jamieson, 2001; Schweizer and Camponovo, 2001; Thumlert and Jamieson, 2014). Furthermore, the hardness of the substratum may also play a significant role, hard layers (such as crusts) just below the weak layer act as stress concentrators in the weak layer (van Herwijnen and Jamieson, 2007; Habermann et al., 2008). Snow hardness is not only related to density but also to temperature, colder layers being harder but less tough (McClung and Schweizer, 1999).

In the following, we show how to compute the skierinduced stress within a multi-layered snowpack taking into account the layering of the overlying snow slab and the substratum. We apply this approach to simplified snow profiles and compare the results to those previously obtained with finite element (FE) simulations (Habermann et al., 2008). Then, the new formulation of the additional skier stress is implemented into the skier stability index ( $\mathrm{SK}_{38}$ ) (Föhn, 1987b; Jamieson and Johnston, 1998) and we evaluated how well the refined skier stability index classified a set of manually observed snow profiles into three classes of stability. Finally, we show, using a case study, the applicability of the refined $\mathrm{SK}_{38}$, which is denoted $\mathrm{SK}_{38}^{\mathrm{ML}}$ (ML = multi-layered) within the 1-D snow cover model SNOWPACK.

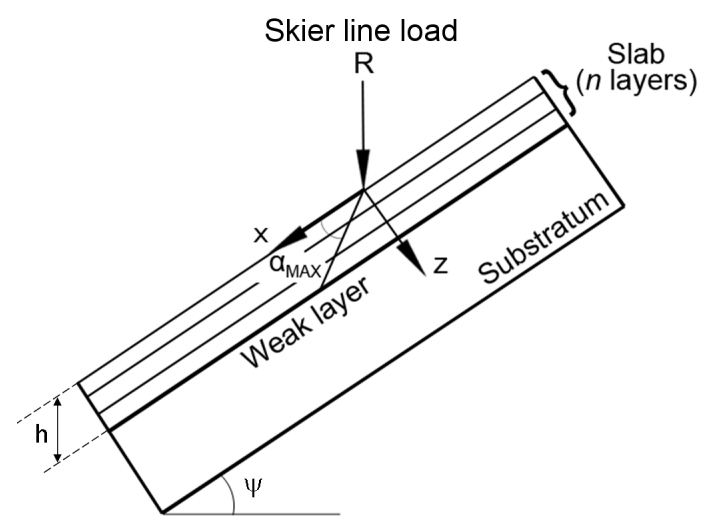

Figure 1. Cross section of a slab showing $R$ as the skier load, $\psi$ the slope angle, $h$ the slab depth and $\alpha_{\max }$ the angle from the skier to the maximum induced shear stress.

\section{Methods}

\subsection{Additional skier stress within a multi-layered snowpack}

Our objective is to compute the additional stress due to a skier in a multi-layered snowpack. The approach proposed by Föhn (1987b), based on the 3-D extension of Boussinesq's analysis (Boussinesq, 1885) for a point load and further adapted for a line load, is only valid for a uniform (constant Young's modulus E) isotropic material. Under these assumptions, Föhn (1987b) derived the skier-induced shear stress according to

$\Delta \tau_{x z}=\frac{2 R \cos \alpha_{\max } \sin ^{2} \alpha_{\max } \sin \left(\alpha_{\max }+\psi\right)}{\pi h \cos \psi}$,

where $R$ is the line load due to a skier, $\psi$ the slope angle, $h$ the slab depth and $\alpha_{\max }$ the angle between the bed surface and the line from the skier to the point of maximum induced shear stress (Fig. 1 and Appendix).

However, the approach proposed by Föhn (1987b) is not accurate for a layered snow cover. For instance, it is clear that a skier will have less influence on the rest of the snowpack if the surface layers are more rigid. Consequently, the stresses in the underlying layers would be lower than the values derived with Boussinesq's approach. In the avalanche domain, this effect is often called "bridging". Thumlert and Jamieson (2014) recently coupled the "bridging index" introduced by Schweizer and Jamieson (2003) to the classical skier stability index. This "bridging index" corresponds to the sum of the hardness of the different slab layers, weighted by the respective depth.

Rather than defining a new empirical index we will directly take into account the effects of snow stratigraphy into the skier stability index by computing the skier-induced stress in a layered medium. Habermann et al. (2008) used the finite element method (FEM) to compute the stress due 
(a)

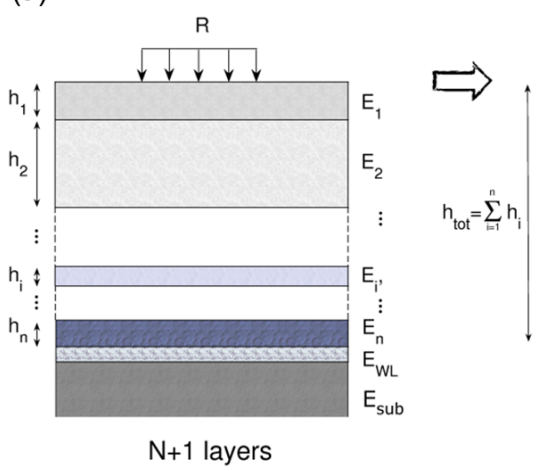

(b)

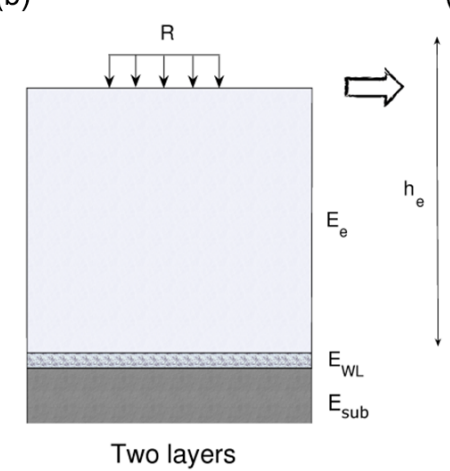

(c)

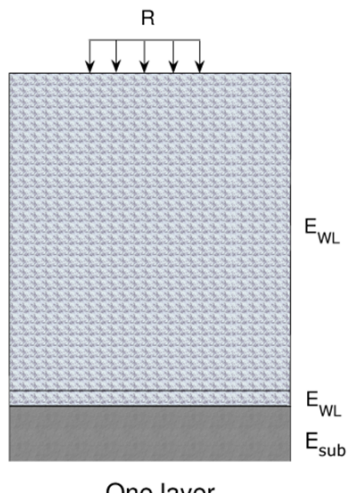

Figure 2. Scheme of the presented method which consists in substituting a multi-layer system (a) by an equivalent two-layer system (b) which can in turn be substituted in a one layer uniform system (c) for which the influence of a skier represented by a line load applied at the top free surface can be computed using Boussinesq's theory (Eq. 1).

to a skier at the depth of the weak layer within a snow cover composed of 3 slab layers and a substratum (Fig. 1) for different typical configurations. In particular, they showed that, compared to a uniform slab, the skier-induced stress may decrease by a factor 2 when taking into account slab stratigraphy.

General theory of elasticity in a layered system can be found in Bufler (1971) and was first discussed by Burmister (1945). These authors used the integral transform method to determine the elastic deformation fields in a layered system for different types of loads. More recently, Fretigny and Chateauminois (2007) generalized these results into a more compact matrix formulation. However, the complexities in the resolution of the contact problem make the applicability of this approach difficult for the cases with more than two layers.

Lately, Vakili (2008) combined two approaches to simplify the calculations of the stresses in a layered system for the practical design of road pavements and overlays: (i) substitution of the upper two layers of a three-layer system by a single layer of equivalent Young's modulus (De Barros, 1966); (ii) replacement of the upper layer of the two-layer system by an equivalent depth $h_{\mathrm{e}}$ of the underlying material (Palmer and Barber, 1941). Vakili (2008) confirmed the accuracy of this approach by comparing the results to the rigorous analytical solution (error less than $5 \%$ ) for a three-layer system. Recently, this method was successfully applied by McCartney et al. (2013) for the evaluation of geo-syntheticreinforced flexible pavements.

In this paper, the approach introduced by Vakili (2008) is generalized to a multi-layered system. This system is composed of a weak layer of Young's modulus $E_{\mathrm{WL}}$, underlying $n$ snow slab layers of depth $h_{i}$ and Young's modulus $E_{i}$. If we generalize the result of De Barros (1966), we can replace the $n$ slab layers by an equivalent slab of equivalent Young's modulus $E_{\mathrm{e}}$
$E_{\mathrm{e}}=\left[\frac{\sum_{i=1}^{n} h_{i} \sqrt[3]{E_{i}}}{\sum_{i=1}^{n} h_{i}}\right]^{3}$

and of depth $h_{\text {tot }}$

$h_{\mathrm{tot}}=\sum_{i=1}^{n} h_{i}$.

The system is thus reduced to two layers. An illustration of this transformation is shown in Fig. $2 a$ and $b$.

Then, Palmer and Barber (1941) assumed that the upper layer of this two layers system can be replaced by an equivalent layer with the same elastic properties as the underlying layer (the weak layer in our case) by calculating the equivalent depth:

$h_{\mathrm{e}}=h_{\mathrm{tot}} \sqrt[3]{\frac{E_{\mathrm{e}}}{E_{\mathrm{wL}}}}$.

Figure $2 \mathrm{~b}$ and $\mathrm{c}$ illustrate this two-phase process. Finally, one can compute the skier-induced shear stress $\Delta \tau_{x z}^{\mathrm{ML}}$ by replacing the slab depth $h$ by this equivalent depth $h_{\mathrm{e}}$ in Eq. (1). If we assume a line load $R=500 \mathrm{~N} \mathrm{~m}^{-1}$ and a slope angle $\psi=38^{\circ}$, then Eq. (1) reduces to $\Delta \tau_{x z}^{\mathrm{ML}}=155 / h_{\mathrm{e}}$ in the case of a layered medium.

Furthermore, it has been shown that the substratum also has a great influence on the amount of stress concentrating in the weak layer (van Herwijnen and Jamieson, 2007; Habermann et al., 2008). Hence, this effect was taken into account by computing the additional stress in the middle of the weak layer, taken as the average between the additional stresses at the top and bottom interfaces of the weak layer according to 
Table 1. Material properties of the layers for the simplified snow profiles.

\begin{tabular}{llclc}
\hline $\begin{array}{l}\text { Layer } \\
\text { characteristic }\end{array}$ & $\begin{array}{l}\text { Hand } \\
\text { hardness } \\
\text { index }\end{array}$ & $\begin{array}{c}\text { Density } \\
\rho \\
\left(\mathrm{kg} \mathrm{m}^{-3}\right)\end{array}$ & $\begin{array}{l}\text { Young's } \\
\text { modulus } E \\
(\mathrm{MPa})\end{array}$ & $\begin{array}{c}\text { Poisson's } \\
\text { ratio } v\end{array}$ \\
\hline Soft & F (fist) & 120 & 0.3 & 0.25 \\
Medium & 4F (4 fingers) & 180 & 1.5 & 0.25 \\
Hard & 1F (1 finger) & 270 & 7.5 & 0.25 \\
Weak layer & F- & 100 & 0.15 & 0.25 \\
\hline
\end{tabular}

$\Delta \tau_{x z}^{\mathrm{ML}}=\frac{155}{2}\left(\frac{1}{h_{\mathrm{e}, n}}+\frac{1}{h_{\mathrm{e}, n+1}}\right)$,

where $h_{\mathrm{e}, n}=h_{\mathrm{e}}$ is the equivalent depth of the $n$ slab layers above the weak layer and $h_{\mathrm{e}, n+1}$ the equivalent depth of the $n+1$ layers above the substratum (hence including the slab layers and the weak layer).

Finally, note that according to our method, at the depth of the weak layer, the slab equivalent modulus will be the same for profiles with similar slab layers but with a different layering order. This point will be further discussed.

\subsection{Comparison to simplified snow profiles}

To evaluate the results of the proposed approach, we calculated the refined skier-induced shear stress $\Delta \tau_{x z}^{\mathrm{ML}}$ for five different typical slab profiles with either a hard or soft substratum (Fig. 3). Then we compared the results with those obtained by Habermann et al. (2008) using the finite element method.

For comparing the different approaches, the $k$ value proposed by Habermann et al. (2008) was used. The $k$ value is the ratio of the additional shear stress calculated with the different multi-layered approaches $\left(\Delta \tau_{x z}^{\mathrm{ML}}\right)$ and the maximum additional stress obtained from the classic analytical approach $\left(\Delta \tau_{x z}\right)$ :

$k=\frac{\Delta \tau_{x z}^{\mathrm{ML}}}{\Delta \tau_{x z}}$.

The simplified profiles have the same characteristics and material properties (Table 1) as those used by Habermann et al. (2008). The hand hardness (Fierz et al., 2009) values were assigned corresponding to the layer densities (Geldsetzer and Jamieson, 2001). The Poisson's ratio does not vary significantly for the proposed snow Young's modulus $E$ and density $\rho$ (Smith et al., 1971); thus it was assumed as constant $(v=0.25)$ by Habermann et al. (2008) for the FE simulations and has no influence in our approach. The slab layers have a thickness of $0.12 \mathrm{~m}$, the weak layer of $0.05 \mathrm{~m}$ and the substratum was assumed as semi-infinite. As in Habermann et al. (2008), the penetration depth of the skier was not taken into account for these calculations. The load due to the skier was assumed as a strip load $1 \mathrm{~m}$ long and $0.2 \mathrm{~m}$ wide with a surface normal stress of $3.9 \mathrm{kPa}$.

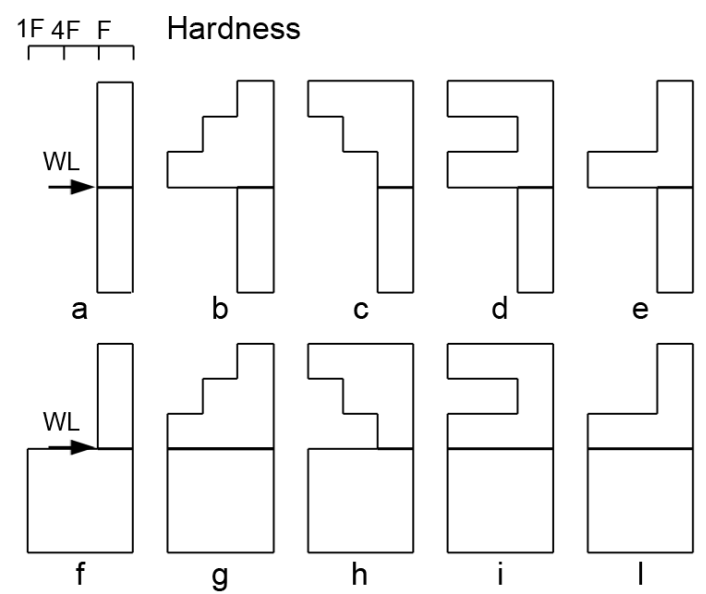

Figure 3. Ten simplified hardness profiles. The profiles from (a) to (e) have a weak base, while from (f) to (l) a strong base. The arrows highlight the depth where the weak layer was located (not to scale). The simplified profiles have the same characteristics as the ones used by Habermann et al. (2008).

\subsection{Refinement of the skier stability index}

To evaluate the effects of the new approach for the additional skier stress considering the multi-layered snowpack we implemented it in the skier stability index $\left(\mathrm{SK}_{38}\right)$ (Föhn, 1987b; Jamieson and Johnston, 1998):

$\mathrm{SK}_{38}=\frac{\tau_{\mathrm{I}, \mathrm{II}}}{\tau_{x z}+\Delta \tau_{x z}}$,

where $\tau_{\mathrm{I}}$ and $\tau_{\mathrm{II}}$ are the shear strength for persistent and nonpersistent grain types, respectively, $\tau_{x z}$ is the shear stress due to the weight of the overlaying slab:

$\tau_{x z}=\rho g h \sin \psi \cos \psi$,

and $\Delta \tau_{x z}$ is the additional shear stress due to the skier (Eq. 1), $h=h_{\text {tot }}=\sum_{i=1}^{n} h_{i}$ is the slab depth (Föhn, 1987b) and $\rho=1 / h_{\text {tot }} \sum_{i=1}^{n} h_{i} \rho_{i}$ the average slab density. The weak layer shear strength depends on the weak layer density according to the power-laws proposed by Jamieson and Johnston (2001) based on shear frame measurements.

For the classical $\mathrm{SK}_{38}$, the snow cover is assumed to be an isotropic uniform material. For the proposed $\mathrm{SK}_{38}^{\mathrm{ML}}, h$ is replaced by $h_{\mathrm{e}}$ (Eq. 4). Both $h$ and $h_{\mathrm{e}}$ can include further refinements such as the effect of ski penetration (Jamieson and Johnston, 1998).

Furthermore, one can compute the depth $h^{*}$ at which the skier's influence becomes negligible, for instance when the refined skier stability index is equal to $90 \%$ of the natural stability index SI: 


$$
\begin{aligned}
\operatorname{SK}_{38}^{\mathrm{ML}} & \left(h^{*}\right)=0.9 \mathrm{SI}\left(h^{*}\right) \\
\rightarrow h^{*}= & {\left[\frac{2 R \cos \alpha_{\max } \sin ^{2} \alpha_{\max } \sin \left(\alpha_{\max }+\psi\right) /(\pi \cos \psi)}{\rho g \sin \psi \cos \psi}\right]^{1 / 2} } \\
& \times\left[\frac{E_{\mathrm{e}}}{E_{\mathrm{WL}}}\right]^{-1 / 6}\left[\frac{1}{\frac{1}{0.9}-1}\right]^{1 / 2} .
\end{aligned}
$$

For a slope angle of $38^{\circ}$ and a skier line load $R=500 \mathrm{~N} \mathrm{~m}^{-1}$, Eq. (10) reduces to

$h^{*}=\left[\frac{2880}{\rho g}\right]^{1 / 2}\left[\frac{E_{\mathrm{e}}}{E_{\mathrm{WL}}}\right]^{-1 / 6}$.

The density $\rho$ of the slab and the ratio of the moduli $E_{\mathrm{e}} / E_{\mathrm{wL}}$ are thus the two most important factors impacting the influence depth $h^{*}$ of a skier.

\subsection{Comparison with field data}

The classic $\mathrm{SK}_{38}$ and the refined $\mathrm{SK}_{38}^{\mathrm{ML}}$ were calculated for 160 manually observed snow profiles collected in the Columbia Mountains of western Canada by researchers from the University of Calgary, each including a rutschblock (RB) stability test (Föhn, 1987a). In addition, the shear strength of the weak layers had been measured using a shear frame (Jamieson and Johnston, 2001). The Young's modulus of the different layers was estimated using the relation proposed by Sigrist (2006):

$E=A\left(\frac{\rho}{\rho_{0}}\right)^{2.94}$,

with $A=968 \mathrm{MPa}$ and the density of ice $\rho_{0}=917 \mathrm{~kg} \mathrm{~m}^{-3}$. To assess the stability information provided by both $\mathrm{SK}_{38}$ and $\mathrm{SK}_{38}^{\mathrm{ML}}$, comparisons between the skier stability indices and RB scores were performed. Concerning the RB, it is known that the score is not the only parameter that should be taken into account to assess snow stability, but the release type - being the other significant parameter (e.g. Schweizer et al., 2008b) - was not consistently recorded.

Furthermore, accounting for the ski penetration depth does not influence the comparison between the two ways to calculate $\Delta \tau_{x z}$ (Eq. 1) namely using either the classic $h$ (slab depth) or the proposed equivalent depth $h_{\mathrm{e}}$ (Eq. 4). However, since the ski penetration depth significantly influences the stability estimate provided by $\mathrm{SK}_{38}$ and $\mathrm{SK}_{38}^{\mathrm{ML}}$, it was taken into account for the comparisons between predicted stability and the RB score.

The compaction due to ski penetration was not considered. Once the penetration depth was determined following the approach proposed by Jamieson and Johnston (1998), the additional stress by a skier was calculated while excluding the top layers that were penetrated by the skis. In the case of the $\mathrm{SK}_{38}^{\mathrm{ML}}$ the ski penetration depth was calculated on the original snow profile before computing the equivalent one layer uniform system.

\subsection{Applicability of the $\mathrm{SK}_{38}^{\mathrm{ML}}$ to the 1-D snow cover model SNOWPACK}

Snow cover modelling can potentially improve both the spatial and temporal resolution of the available data for avalanche forecasters (Lehning et al., 1999). The 1-D snow cover model SNOWPACK (Bartelt and Lehning, 2002; Lehning et al., 2002a, b) was developed for this purpose and in addition to the snow cover stratigraphy provides information on snow stability (Lehning et al., 2004; Monti et al., 2014a; Schweizer et al., 2006). As the $\mathrm{SK}_{38}$ is already calculated within SNOWPACK (Lehning et al., 2004), the proposed approach for the additional skier stress within a multilayered snowpack can easily be implemented.

Furthermore, we will present two examples highlighting the usefulness of $\mathrm{SK}_{38}^{\mathrm{ML}}$ in SNOWPACK. We chose two profiles calculated for the location of two automatic weather stations (AWS) in the region of Davos: Weissfluhjoch (2540 m a.s.1.) and Gatschiefer (2310 m a.s.1.). The two selected simulated snow profiles are both for 21 January 2002; a date for which several manual profiles are available. The regional snow cover stability had been assessed and the verified avalanche danger rated as "Moderate, 2" above $2300 \mathrm{~m}$ a.s.1. on slopes of aspects W-N-E (Schweizer et al., $2003 b)$. For this exemplary analysis, the relative threshold sum approach (Monti et al., 2014a, b) was used to detect the potential weak layers within the simulated snow stratigraphy, then the $\mathrm{SK}_{38}$ and the $\mathrm{SK}_{38}^{\mathrm{ML}}$ were calculated to evaluate the stability at the depth of the weak layer.

\section{Results}

\subsection{Effect of a multi-layered snowpack on the additional stress distribution}

Figure 4 shows the additional shear stress $\Delta \tau_{x z}^{\mathrm{ML}}$ as a function of the ratio $E_{\mathrm{e}} / E_{\mathrm{wL}}$ and of the slab depth $h$. The additional shear stress $\Delta \tau_{x z}^{\mathrm{ML}}$ decreases with increasing moduli ratio $E_{\mathrm{e}} / E_{\mathrm{wL}}$ and slab depth $h$. For the cases in which the slab equivalent modulus $E_{\mathrm{e}}$ is larger than the weak-layer modulus $E_{\mathrm{WL}}$, the additional stress is lower than that predicted by the Boussinesq approach due to the bridging effect.

To assess whether the proposed approach can reproduce the effect of snow layering on the additional stress distribution, we compared our approach to both the analytical solution in a uniform snowpack (Föhn, 1987b) and to finite element simulations performed by Habermann et al. (2008) (Fig. 5). Our approach predicts higher stresses at the depth of the weak layer if the substratum is hard rather than soft. This result is in agreement with the simulation results by Habermann et al. (2008) and has been suggested by van Herwijnen and Jamieson (2007). The multi-layered additional stress $\Delta \tau_{x z}^{\mathrm{ML}}$ was highest at the depth of the weak layer for the profile with a soft slab and a hard substratum (Figs. 3f and 5f). 

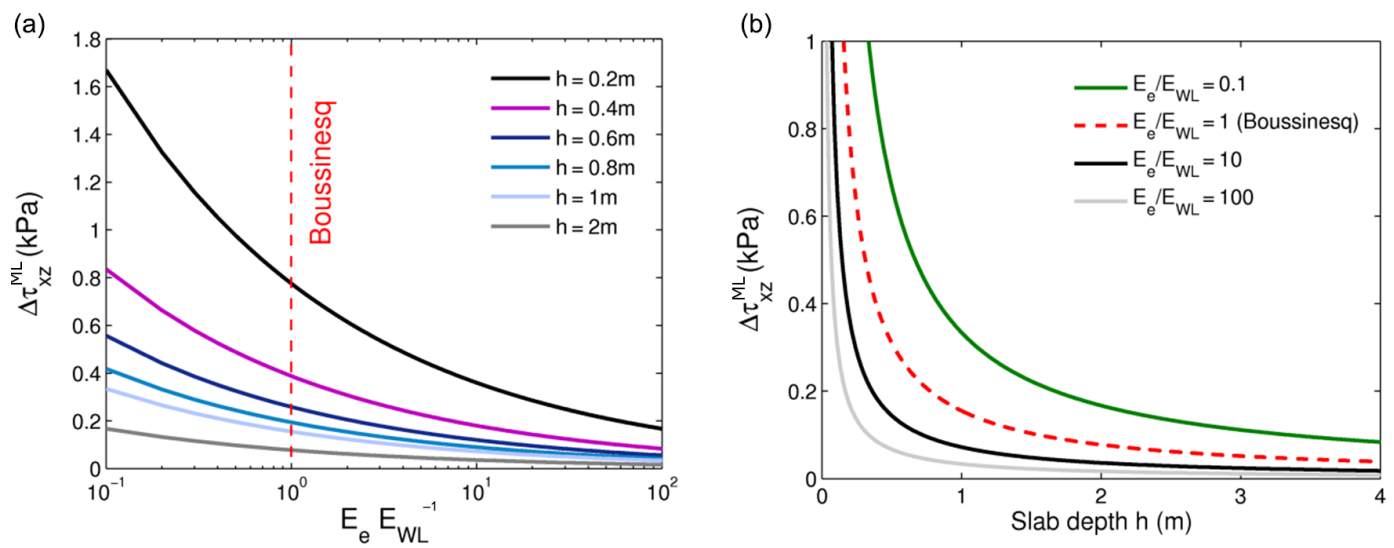

Figure 4. The skier-induced stress $\Delta \tau_{x z}$ (in $\mathrm{kPa}$ ) (a) as a function of the ratio between the equivalent Young's modulus $E_{\mathrm{e}}$ and the weak layer Young's modulus $E_{\mathrm{WL}}$ for different values of slab depth $\left(\psi=38^{\circ}\right.$ and $\left.R=500 \mathrm{~N} \mathrm{~m}^{-1}\right)$, and (b) as a function of the slab depth $h$ for different values of the ratio $E_{\mathrm{e}} / E_{\mathrm{WL}}\left(\psi=38^{\circ}\right.$ and $\left.R=500 \mathrm{~N} \mathrm{~m}^{-1}\right)$.

On the contrary, the lowest stress at the depth of the weak layer was recorded for the profile with hard layers within the slab and a soft substratum (Figs. 3d and 5d), which was again in agreement with Habermann et al. (2008). Generally, the $k$ values of the different profiles were consistent with those reported by Habermann et al. (2008). However, our approach cannot discriminate between the profiles with upper layers having the same equivalent elastic modulus (Eq. 2) but a different order of the layering (Fig. 3b, c and g, h). For the profiles characterized by a soft substratum (Fig. 3a-e) the agreement between the $k$ values calculated with $\Delta \tau_{x z}^{\mathrm{ML}}$ and with the FE simulations of Habermann et al. (2008) was very satisfactory. For the profiles with a hard substratum (Fig. 3f1) the skier-induced stress at the weak layer depth $\Delta \tau_{x z}^{\mathrm{ML}}$ was slightly larger, especially for profile $\mathrm{f}$. However, the differences in the additional stress computed from FE simulations and with our simplified approach were in general rather small.

\subsection{Effect of a multi-layered snowpack on the skier stability index}

To assess the effect of the multi-layer character of the snowpack on the stability calculation with the new approach, we computed the skier stability index as a function of slab depth $h$ for different values of $E_{\mathrm{e}} / E_{\mathrm{wL}}$ assuming a slab density $\rho=200 \mathrm{~kg} \mathrm{~m}^{-3}$ and the weak layer shear strength $\tau_{\text {II }}=500 \mathrm{~Pa}$ (Fig. 6a). If the slab is much stiffer than the weak layer, then the stability index is larger than in the case of a uniform snowpack; this is the bridging effect. This effect can have a strong influence on skier stability if the weak layer is not too deeply buried in the snowpack (i.e. for slab depths thinner than $\sim 1 \mathrm{~m}$ ). If the slab depth is thicker than $\sim 1 \mathrm{~m}$, the load induced by the skier becomes negligible compared to the load of the slab. However, one should note that this critical slab depth value depends on the density of the slab; the higher the density, the lower the influence depth of the skier $h^{*}$, as illustrated in Fig. 6b where the $90 \%$ influence depth $h^{*}$ as a function of slab density for different ratios of the moduli (according to Eq. 11) is shown. As already pointed out by Habermann et al. (2008), this depth can be less than half than that of a uniform snow cover. Furthermore, slab density is also an important factor since it can decrease the depth of the influence zone $h^{*}$ by more than $40 \%$ from a soft to hard slab layer. One should note that, for the sake of simplicity and clarity of these results, this parametric analysis does not take into account the link between slab density and Young's modulus. Consequently, the Young's modulus being an increasing function of density, one can expect an even more important decrease of $h^{*}$ with density. For the same reasons, the weak layer shear strength was taken constant $\left(\tau_{\text {II }}=500 \mathrm{~Pa}\right)$, independent of weak layer density. In general, weak layer density increases with increasing depth due to settlement, which would also improve stability.

\subsection{The $\mathrm{SK}_{38}^{\mathrm{ML}}$ applied to manually observed data}

The refined parametrization of the additional load due to a skier $\Delta \tau_{x z}^{\mathrm{ML}}$ was implemented into the classical skier stability index and applied to evaluate point stability for 160 manually observed profiles. The profiles were grouped into three classes based on the RB scores. For the sake of simplicity, we denoted the stability as "poor" for RB scores of 1 and 2, "fair" for RB scores of 3 and 4, and "good" for RB scores of 5, 6 and 7. In Fig. 7 the distributions of both the $\mathrm{SK}_{38}^{\mathrm{ML}}$ and $\mathrm{SK}_{38}$ for the three different stability classes are shown. The stability values calculated with $\mathrm{SK}_{38}^{\mathrm{ML}}$ as well as with $\mathrm{SK}_{38}$ were similar for each of the three stability classes. According to the thresholds proposed by Föhn (1987a) and Jamieson and Johnston (1998), both $\mathrm{SK}_{38}^{\mathrm{ML}}$ and $\mathrm{SK}_{38}$ were able to discriminate between the different classes: "poor" $\left(S^{\prime}<1\right)$, "fair" $\left(1 \leq S^{\prime} \leq 1.5\right)$ and "good" $\left(S^{\prime}>1.5\right)$. Furthermore, a 

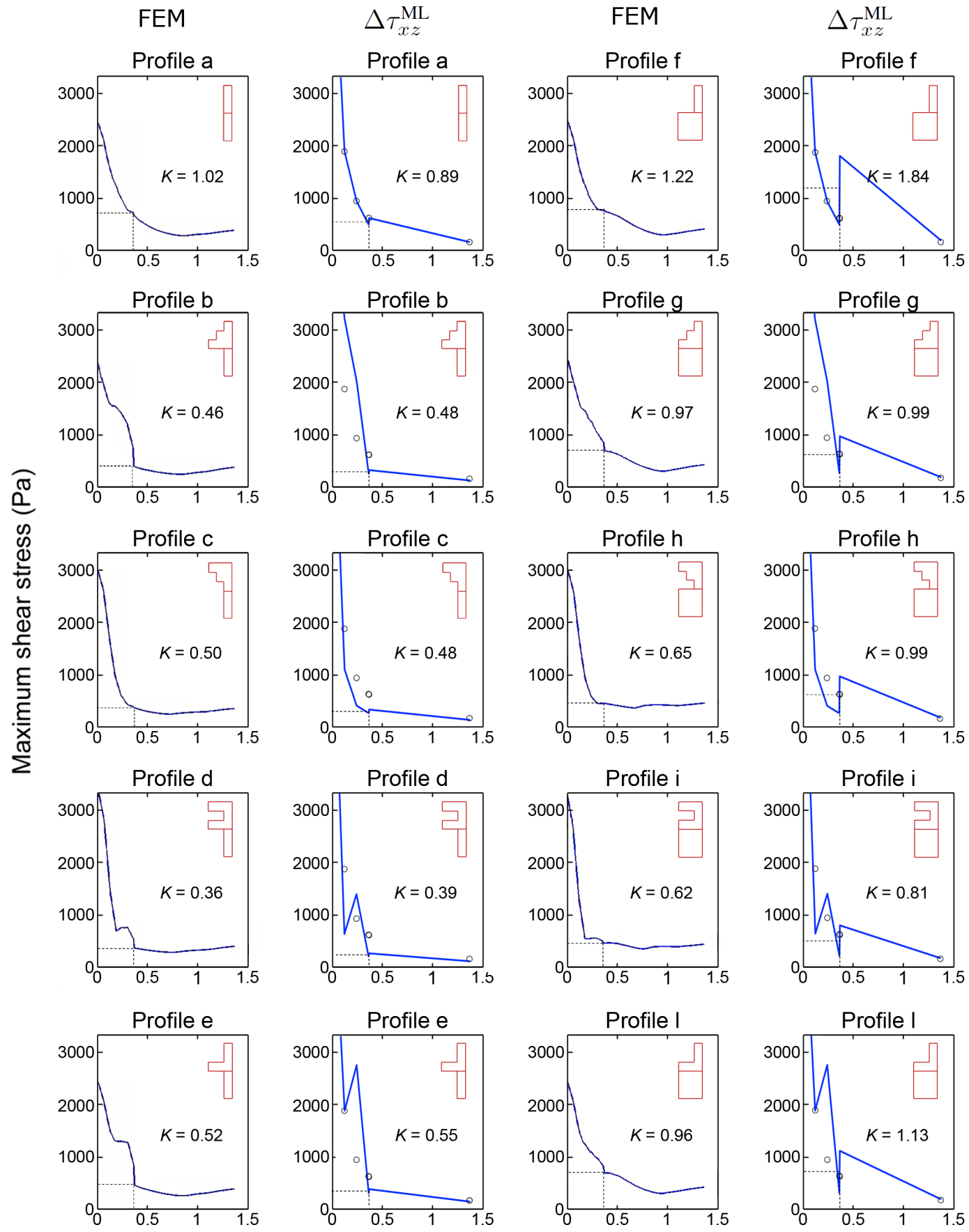

Depth $(m)$

Figure 5. Maximum shear stress vs. depth calculated with FEM (Habermann et al., 2008) and with the proposed approach $\left(\Delta \tau_{x z}^{\mathrm{ML}}\right)$ for 10 simplified profiles shown in red in the upper right corner. The dotted lines indicate the weak layer position, the black circles indicate the values of the classical analytical solution (Föhn, 1987a).

Mann-Whitney $U$ test allowed to verify the discriminating power. Indeed, for the $\mathrm{SK}_{38}^{\mathrm{ML}}$, the $p$ value was less than $5 \%$ for all stability classes combinations ("poor-fair": $p=0.019$, "fair-good": $p=1.1 \times 10^{-5}$, "good-poor": $p=3.5 \times 10^{-5}$ ). Similar but slightly lower values were found for the standard
SK $_{38}$ ("poor-fair": $p=0.017$, "fair-good": $p=0.9 \times 10^{-5}$, "good-poor": $p=2.0 \times 10^{-5}$ ).

The largest difference between the $\mathrm{SK}_{38}^{\mathrm{ML}}$ and $\mathrm{SK}_{38}$ was found for the class "poor" for which the $\mathrm{SK}_{38}^{\mathrm{ML}}$ values were slightly lower than 1 (median value of 0.84 ), whereas the 

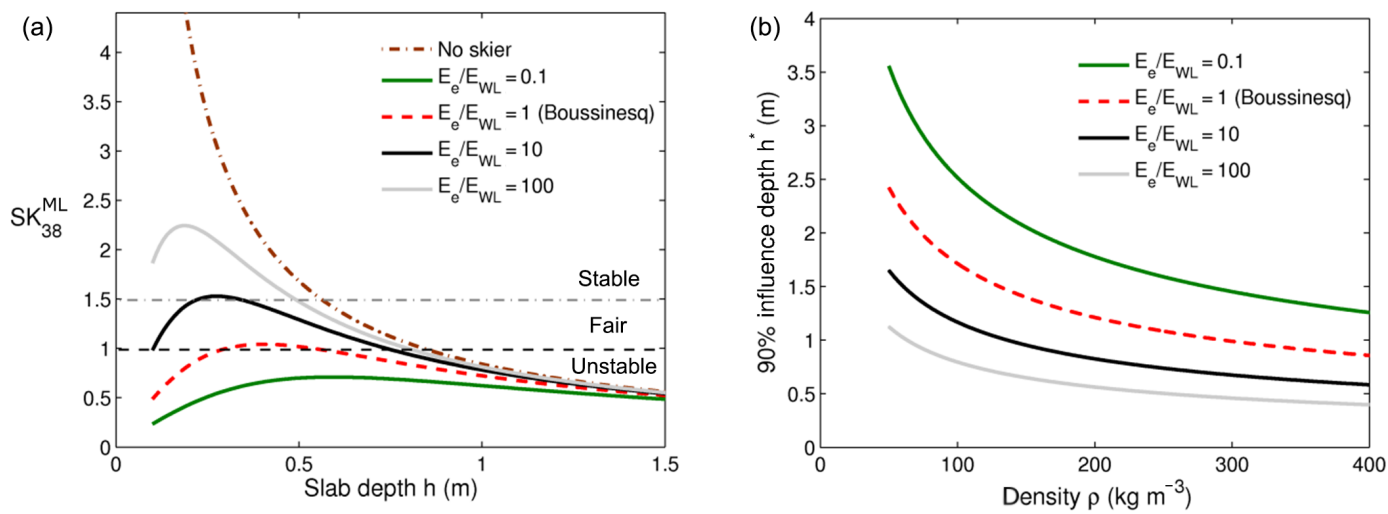

Figure 6. (a) The skier stability index $\mathrm{SK}_{38}^{\mathrm{ML}}$ as a function of the slab depth $h$ and for different values of the ratio $E_{\mathrm{e}} / E_{\mathrm{WL}}$ and for a case without a skier $\left(\psi=38^{\circ}, R=500 \mathrm{~N} \mathrm{~m}^{-1}, \rho=200 \mathrm{~kg} \mathrm{~m}^{-3}, \tau_{\mathrm{II}}=500 \mathrm{~Pa}\right)$. (b) The $90 \%$ influence depth as a function of slab density for different ratios of the slab and weak-layer moduli (according to Eq. 11).

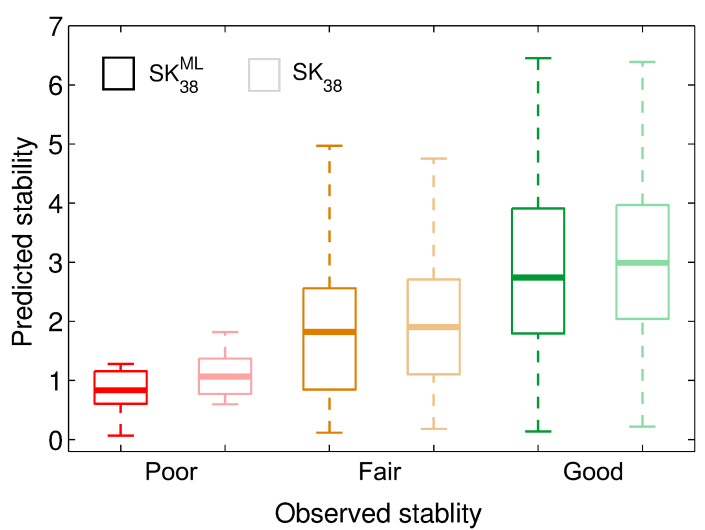

Figure 7. $\mathrm{SK}_{38}^{\mathrm{ML}}$ (left) vs. $\mathrm{SK}_{38}$ (right) predicted stability distributions per observed stability class (poor: manual profiles with RB scores 1 and 2, $N_{\text {poor }}=10$; fair: manual profiles with RB scores 3 and 4, $N_{\text {fair }}=53$; good: manual profiles with RB scores 5, 6 and $\left.7, N_{\text {good }}=97\right)$. Boxes span the interquartile range from 1 st to 3rd quartile with a horizontal line showing the median. Whiskers show the range of observed values that fall within 1.5 times the interquartile range above and below the interquartile range.

$\mathrm{SK}_{38}$ was slightly higher than 1 (median value 1.05 ), thus predicting higher stability (Fig. 7).

To illustrate the differences between the two indices, we calculated the ratio between $\mathrm{SK}_{38}^{\mathrm{ML}}$ and $\mathrm{SK}_{38}$ for the three observed stability classes (Fig. 8). Generally, $\mathrm{SK}_{38}^{\mathrm{ML}}$ showed lower values than $\mathrm{SK}_{38}$, the differences being higher for the lower stability classes; for the stability class "poor" on average the values of $\mathrm{SK}_{38}^{\mathrm{ML}}$ were lower than the values of $\mathrm{SK}_{38}$ by $30 \%$ (Fig. 8). Whereas for the stability class "good" the difference was less than $10 \%$.

In Fig. 9 we present a scatter plot of the ratio between the $\mathrm{SK}_{38}^{\mathrm{ML}}$ (which takes into account snowpack layering) and the standard $\mathrm{SK}_{38}$ as a function of $E_{\mathrm{e}} / E_{\mathrm{wL}}$ and $E_{\mathrm{sub}} / E_{\mathrm{wL}}$. The contour lines indicate the general trend calcu-

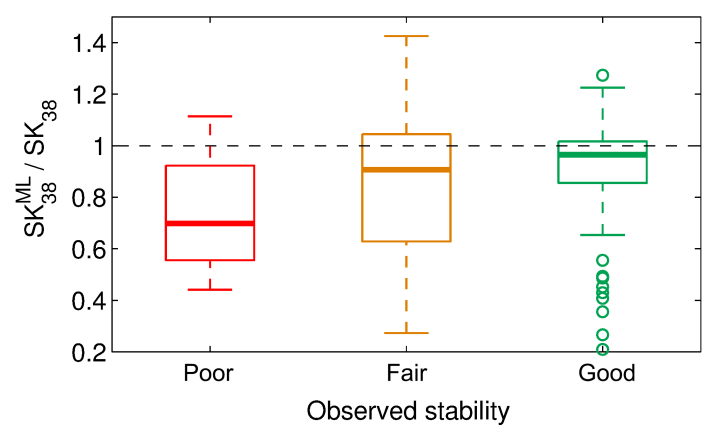

Figure 8. Distributions of the ratio between $\mathrm{SK}_{38}^{\mathrm{ML}}$ and $\mathrm{SK}_{38}$ per observed stability class (poor: manual profiles with RB scores 1 and 2, fair: manual profiles with RB scores 3 and 4, good: manual profiles with RB scores 5, 6 and 7). Four outliers ( $>1.5$ ) not shown.

lated with the average values of the data set: $\left\langle h_{\mathrm{tot}}\right\rangle=0.76 \mathrm{~m}$, $\left\langle h_{\mathrm{wL}}\right\rangle=0.0147 \mathrm{~m},\left\langle E_{\mathrm{wL}}\right\rangle=1.5 \mathrm{MPa}$.

First, we can notice as already pointed out above, that more than $50 \%$ of the data showed lower values of the equivalent slab modulus $E_{\mathrm{e}}$ compared to the weak-layer modulus $\left(E_{\mathrm{e}} / E_{\mathrm{WL}}<1\right)$ and can thus be characterized as soft slabs. For these soft slabs, $\mathrm{SK}_{38}^{\mathrm{ML}}$ was up to $40 \%$ lower than $\mathrm{SK}_{38}$. In addition, the ratio $\mathrm{SK}_{38}^{\mathrm{ML}} / \mathrm{SK}_{38}$ was mostly lower than 1 ( $66 \%$ of the data), which was a result of a combination between relatively soft slabs and a hard substratum which is conducive to stress concentration at the weak layer.

Furthermore, for most of the cases with equivalent slabs harder than the respective weak layer, the layered $\mathrm{SK}_{38}^{\mathrm{ML}}$ was only slightly larger than the standard $\mathrm{SK}_{38}$ (with a ratio between 1 and 1.4). However, for a few cases (6 in total highlighted with a white arrow on Fig. 9), the layered $\mathrm{SK}_{38}^{\mathrm{ML}}$ was more than 2.5 times higher than $\mathrm{SK}_{38}$ because of a hard equivalent slab and/or a relatively soft substratum. In this configuration, little stress was transmitted to the depth of the weak layer, resulting in a significant increase of the stabil- 


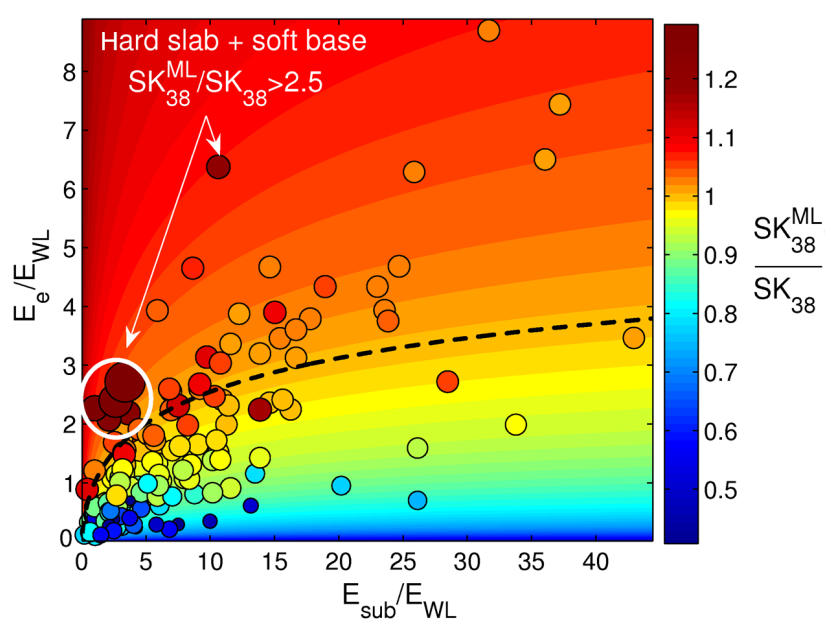

Figure 9. Scatter plot of $\mathrm{SK}_{38}^{\mathrm{ML}} / \mathrm{SK}_{38}$ as a function of $E_{\mathrm{e}} / E_{\mathrm{WL}}$ and $E_{\mathrm{sub}} / E_{\mathrm{WL}}$. The colour and size of the dots relates to the ratio between $\mathrm{SK}_{38}^{\mathrm{ML}}$ and $\mathrm{SK}_{38}$. The contour plot represents average values (representative of the data set) of slab depth $\left(\left\langle h_{\text {tot }}\right\rangle=0.76 \mathrm{~m}\right)$ weak layer thickness $\left(\left\langle h_{\mathrm{wL}}\right\rangle=0.0147 \mathrm{~m}\right)$, weak layer Young's modulus $\left(\left\langle E_{\mathrm{wL}}\right\rangle=1.5 \mathrm{MPa}\right)$. Arrows point to the few cases for which the bridging effect was substantial $\left(\mathrm{SK}_{38}^{\mathrm{ML}} / \mathrm{SK}_{38}>2.5\right)$. The dashed line corresponds to $\mathrm{SK}_{38}^{\mathrm{ML}} / \mathrm{SK}_{38}=1$.

ity index. Yet, this configuration was found for only 6 out of 160 cases. Probably with a data set collected above the tree line, hard slabs would have been more frequently found than observed in the Canadian data set.

\subsection{The $\mathrm{SK}_{38}^{\mathrm{ML}}$ implemented into the snow cover model SNOWPACK}

The $\mathrm{SK}_{38}^{\mathrm{ML}}$ can be calculated for each layer of the snowpack. In Fig. 10, two selected examples of simulated snow stratigraphy for 21 January 2002 are shown. The verified regional avalanche danger in the vicinity of the AWS was rated as "Moderate; 2". Even if the avalanche danger was only "Moderate" the snow cover (snow depth: $110-120 \mathrm{~cm}$ ) was quite weak with two unstable parts: one about $40 \mathrm{~cm}$ from the snow surface and one near the base of the snowpack, both layers consisted of persistent grain types. However, no significant snowfall was recorded the past month, explaining the relatively low avalanche danger. The relative threshold sum approach (RTA, Monti et al., 2014a) highlighted a potential weak layer consisting of faceted crystals about $40 \mathrm{~cm}$ deep in both simulated profiles. For the simulated profile at Weissfluhjoch (Fig. 10a), the detected weak layer was found at a depth of $39 \mathrm{~cm}$ and both the $\mathrm{SK}_{38}^{\mathrm{ML}}$ and $\mathrm{SK}_{38}$ predicted a stability of 1.1 (fairly stable). At the weak layer depth the multi-layered additional stress $\Delta \tau_{x z}^{\mathrm{ML}}$ was $680 \mathrm{~Pa}$ while the $\Delta \tau_{x z}$ was $690 \mathrm{~Pa}$ with a slab-induced stress $\tau_{x z}$ of $416 \mathrm{~Pa}$; thus the difference between the two additional stresses due to a skier was too small to cause any difference in the predicted stability. In this example, the new approach did not make a difference for the stability evaluation of the weak layer; however a difference in the overload assessment within the upper slab layers is noticeable since $\mathrm{SK}_{38}^{\mathrm{ML}}$ becomes higher than $\mathrm{SK}_{38}$ for layers closer to the surface. With the proposed approach the increase of stability within the upper part of the snowpack is not only related to the distance from the load application line (from the ski penetration depth) but is influenced by the different slab layers accounting for the so-called "bridging effect".

In the second example (Fig. 10b) the simulation was performed for the Gatschiefer AWS. The differences between the skier overload predicted at the slab layers is more important than for the previous example. For this case, the stability assessment for the weak layer (depth: $37 \mathrm{~cm}$ ) is different: 1.15 for the $\mathrm{SK}_{38}^{\mathrm{ML}}$, resulting in a "fair" stability, and 0.98 for the $\mathrm{SK}_{38}$, suggesting "poor" stability. At the depth of the weak layer the multi-layered additional stress $\Delta \tau_{x z}^{\mathrm{ML}}$ was $603 \mathrm{~Pa}$, while $\Delta \tau_{x z}$ was $774 \mathrm{~Pa}$ with a slab-induced stress $\tau_{x z}$ of $382 \mathrm{~Pa}$; thus the difference between the two additional stresses due to a skier was sufficient to influence the stability assessment (since the values were close to the threshold of 1). Within the simulated snow profile shown in Fig. 10b the RTA detected a second potential weak layer near the base of the snow cover. In this case the influence depth was largely exceeded so no significant differences between the two approaches was found. However, it is interesting to notice that even if the RTA detected the layer as potentially unstable from a structural point of view it was again classified as "fair" by the skier stability indices $\left(\mathrm{SK}_{38}=\mathrm{SK}_{38}^{\mathrm{ML}}=1.3\right)$. This is a typical example of how the structural and shear strength approaches are complementary.

\section{Discussion}

The proposed approach to assess the additional stress by a skier within a multi-layered snowpack $\left(\Delta \tau_{x z}^{\mathrm{ML}}\right)$ is simple and easy to apply both to manually observed and simulated snow profiles. This approach integrates in a single index both the skier additional load and the so-called "bridging effect" solving semi-analytically stresses in a multi-layered medium. To understand the proposed approach, we tested it on $10 \mathrm{sim}$ plified snow profiles (Fig. 3) for which FE simulations were performed by Habermann et al. (2008). The results are satisfactory especially for the profiles characterized by a soft substratum (Fig. 3a-e); larger differences were recorded for the profiles with a hard substratum (Fig. $3 \mathrm{f}-1$ ) but still the results seem very reasonable. These differences may be explained by the simplified approach we chose for the substratum influence (averaging the stress at the depth of the weak layer with the stress at the upper interface of the substratum). Further refinements of this assumption may improve the results. The major limitation of the proposed method is the fact that it is not able to discriminate between profiles with similar equivalent elastic modulus but with different se- 

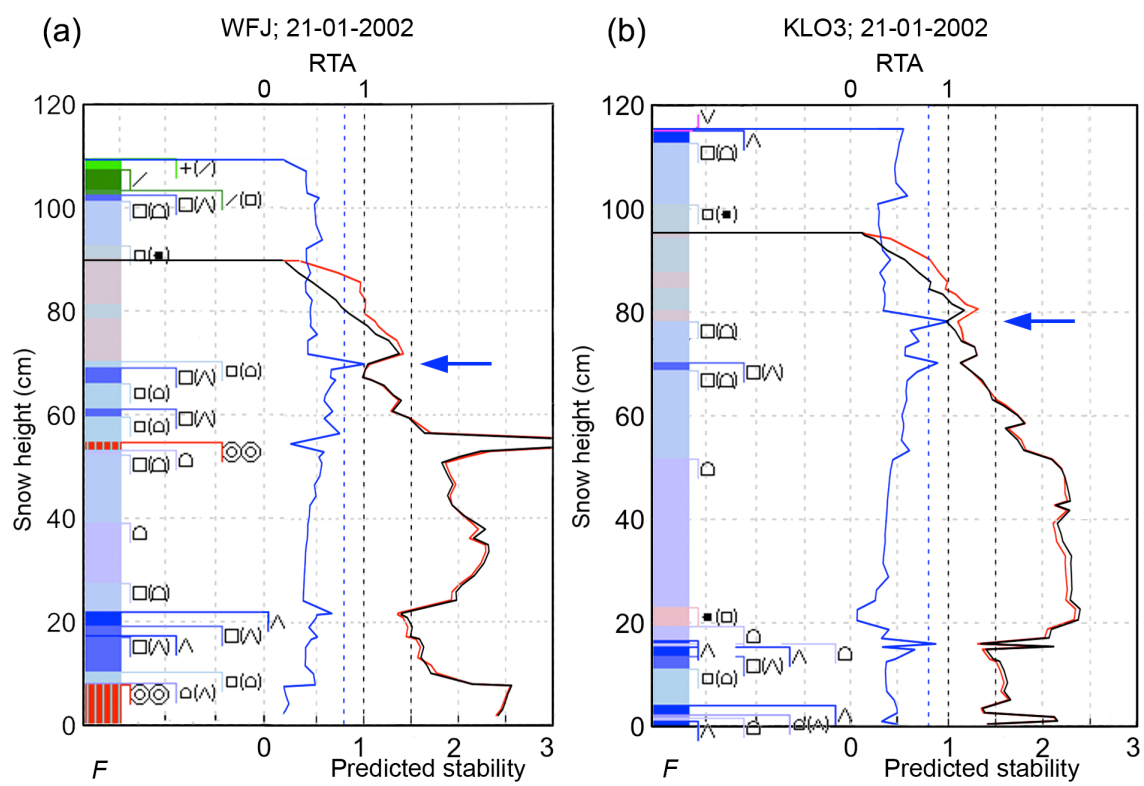

Figure 10. Simulated snow profiles for (a) Weissfluhjoch and (b) Gatschiefer. Grain shape (F) is shown using the symbols and the colours according to the international snow classification (Fierz et al., 2009). The blue solid line is the RTA (Monti et al., 2014a) and was used to detect potential weak layers from a structural point of view (values higher than the blue dashed line). The blue arrow highlights the potential weak layer depth. Black solid line is the $\mathrm{SK}_{38}$ index while the red solid line represents the refined $\mathrm{SK}_{38}^{\mathrm{ML}}$ index.

quence of the layers (profiles b vs. c and g vs. h in Fig. 3). This aspect is particularly limiting for profiles with a hard substratum and a slab for which the hardness decreases with increasing depth (e.g. profile h). In this case, which might occur with increasing wind speeds or temperature during a snowfall, our approach overestimates the stress due to a skier at the depth of the weak layer. Hence, our new stability index would be lower than that predicted by the finite element method (FEM), for instance.

The next step was implementing the multi-layered additional shear stress into the classical skier stability index $\left(\Delta \tau_{x z}^{\mathrm{ML}}\right)$ and testing it on manually observed profiles that include a rutschblock test (RB). To simplify the interpretation, the results were grouped based on the RB score into three stability classes "poor", "fair" and "good". Both the refined $\mathrm{SK}_{38}^{\mathrm{ML}}$ and the $\mathrm{SK}_{38}$ were able to discriminate between the classes and, in general, provided similar results. This can be judged as positive since the $\mathrm{SK}_{38}^{\mathrm{ML}}$ does not overturn the $\mathrm{SK}_{38}$ but should just improve it in particular conditions, i.e. when a hard layer or crust is present within the slab. The data set we used, collected in the Columbia Mountains of western Canada had some limitations. In fact, few profiles with hard slabs were represented probably since the profiles were collected near or below the tree line rather than in the alpine where the wind effect would be more prominent. The same problem was found by Habermann et al. (2008), who used a smaller data set but from the same area. The $\mathrm{SK}_{38}^{\mathrm{ML}}$ values were generally lower than the ones from the classical $\mathrm{SK}_{38}$ (Fig. 7). This finding requires that the equivalent elastic mod- ulus of the slab (Eq. 2) is lower than the elastic modulus of the weak layer.

However, even if the data set included few cases where the "bridging effect" was particularly significant, for profiles with an observed "poor" stability, the $\mathrm{SK}_{38}$ performed slightly worse (median value of predicted stability 1.05 ) than the $\mathrm{SK}_{38}^{\mathrm{ML}}$ (median value 0.84 ). Indeed, the largest differences between $\mathrm{SK}_{38}^{\mathrm{ML}}$ and $\mathrm{SK}_{38}$ were recorded for the profiles with poor stability (Fig. 8) for which $\mathrm{SK}_{38}^{\mathrm{ML}}$ predicted smaller values and thus more frequently unstable conditions. In contrast, the differences were low if not almost null for the more stable profiles. Hence, our results suggest that the discriminating power of the multi-layered skier stability index $\mathrm{SK}_{38}^{\mathrm{ML}}$ is larger than for the standard $\mathrm{SK}_{38}$.

Finally, exploring the applicability of the $\mathrm{SK}_{38}^{\mathrm{ML}}$ to the simulated profiles was straightforward since for each layer within a simulated profile all the parameters required to compute the stability index are available, thus allowing to follow the skier additional stress layer by layer. From the exemplary analysis, we suggest that the proposed approach is valuable not only for predicting the stability of the weak layer but for describing the stress distribution within the slab. A valuable issue of this approach is that it is based on parameters fully simulated from the model (e.g. snow density). On the other hand, the difficulties of SNOWPACK in simulating layers with low density in the lower part of the snowpack (Monti et al., 2014a) as well as wind-induced snow drift effects (which are oversimplified in SNOWPACK, Bartelt and Lehning, 2002) presently limits the full potential of the 
proposed approach. Coupling the relative threshold sum approach (Monti et al., 2014a) for detecting potential weak layers from a structural point of view and the multi-layered skier stability index $\mathrm{SK}_{38}^{\mathrm{ML}}$ for evaluating the stability seems to be a promising method but verification and new developments (e.g. snow drift effects in SNOWPACK) will be required to fully assess the performance of this combined approach.

\section{Conclusions}

The slab avalanche release probability in terms of failure initiation has been quantified by several approaches, most of them assuming a uniform slab layer above the weak layer (Föhn, 1987b; Jamieson and Johnston, 1998). We proposed and tested a simple approach to account for the skier additional stress within a multi-layered snowpack. The model was tested on simplified snow profiles and compared to FE simulations showing consistent results - except that the sequence of layering in the slab cannot be replicated. It was implemented into the classical skier stability index and then applied on both manually observed snow profiles including a stability test and on simulated snow profiles. The refined skier stability index $\left(\mathrm{SK}_{38}^{\mathrm{ML}}\right)$ discriminated well between different stability classes.
Small but important improvements in the evaluation of the skier stability were observed compared to the results obtained with the classical skier stability index $\left(\mathrm{SK}_{38}\right)$. Larger differences can be expected for profiles characterized by hard slabs. For the profiles classified as "poor", the median value of the $\mathrm{SK}_{38}^{\mathrm{ML}}$ was lower than that obtained with the classical index allowing a slightly better discrimination. Finally, we exemplarily showed the applicability of our model to simulated snow stratigraphy. In the future, some efforts will be made to consider the effect of the order of layering on the skier-induced stress. This current limitation of our model tends to overestimate the additional stress due to a skier in particular for cases with a hard substratum and a slab whose hardness decreases with increasing depth. In addition, it would be interesting to apply the proposed approach for describing the additional stress induced by a skier within a multi-layered snowpack with more complex models, taking into account the mixed-mode failure behaviour of the weak layer (Reiweger et al., 2015) as well as crack propagation (Reuter et al., 2015). 


\section{Appendix A: Calculation of the additional shear stress and the peak shear angle $\alpha_{\text {max }}$}

In this appendix, we show how to compute the additional shear stress due to a line load of intensity $R$ and the angle $\alpha_{\max }$ where the stress intensity is maximal. This derivation has previously been presented by Schweizer (1997), a technical report which is not accessible. The solution for a point load on a semi-infinite horizontal half space was given by Boussinesq (1885) and further adapted for a linear load. However, the extension of Boussinesq's theory to the case of an inclined slope (slope angle $\psi$ ) was first performed by Flamant (1892) by modifying the three-dimensional solution of Boussinesq. The additional stresses predicted by Flamant's solution in polar coordinates for a radius $r$ and an angle $\alpha$ (Fig. 1) are given by

$\Delta \sigma_{r r}=\frac{2 c_{1} \cos \alpha}{r}+\frac{2 c_{2} \sin \alpha}{r}$,

$\Delta \sigma_{r \psi}=0$,

$\Delta \sigma_{\psi \psi}=0$,

where $c_{1}$ and $c_{2}$ are constants determined from the boundary conditions and satisfy the following:

$R_{x}+2 \int_{0}^{\pi}\left(c_{1} \cos \alpha+c_{2} \sin \alpha\right) \cos \alpha d \alpha=0$,

$R_{z}+2 \int_{0}^{\pi}\left(c_{1} \cos \alpha+c_{2} \sin \alpha\right) \sin \alpha d \alpha=0$.

Hence by solving Eqs. (A4) and (A5), we can derive the expression of $\Delta \sigma_{r r}$ as follows:

$$
\begin{aligned}
\Delta \sigma_{r r} & =-\frac{2 R}{\pi r}[\sin \psi \cos \alpha+\cos \psi \sin \alpha] \\
& =-\frac{2 R}{\pi h \cos \psi} \sin \alpha \sin (\alpha+\psi) .
\end{aligned}
$$

Then, by changing the coordinate system from polar to Cartesian, the additional stress along the $\mathrm{x}-\mathrm{z}$ plane for a given depth $h$ and slope angle $\psi$ is given by

$$
\begin{aligned}
\Delta \tau_{x z} & =\Delta \sigma_{r r} \sin \alpha \cos \alpha \\
& =-\frac{2 R}{\pi h \cos \psi} \sin ^{2} \alpha \sin (\alpha+\psi) \cos \alpha .
\end{aligned}
$$

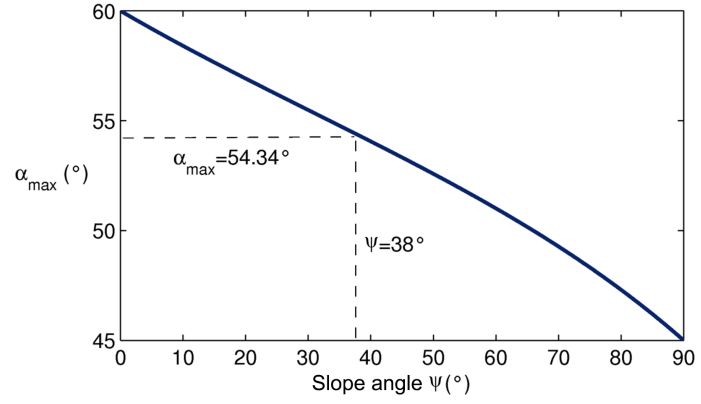

Figure A1. Angle of maximum shear stress $\alpha_{\max }$ vs. slope angle $\psi$.

The additional stress $\Delta \tau_{x z}$ is a function of the angle $\alpha$. In order to find the peak shear stress acting in the snow cover, Eq. (A7) has to be differentiated with respect to $\alpha$ and the values of $\alpha_{\max }$ can be obtained such as the resulting equation equals zero:

$\frac{\partial\left(\Delta \tau_{x z}\right)}{\partial \alpha}=\frac{2 R}{\pi h \cos \psi}\left[\begin{array}{c}2 \sin \alpha \cos ^{2} \alpha \sin (\alpha+\psi) \\ -\sin ^{3} \alpha \sin (\alpha+\psi) \\ +\sin ^{2} \alpha \cos \alpha \cos (\alpha+\psi)\end{array}\right]=0$.

Equation (A8) was numerically solved using Matlab, which gives the relationship between $\alpha_{\max }$ and the slope angle $\psi$ (Fig. A1). For slope angles of 0 and $90^{\circ}$, the resulting values of $\alpha_{\max }$ are 60 and $45^{\circ}$, respectively. These two extreme cases correspond to the cases of a purely vertical and a horizontal line load in flat terrain. The values in Fig. A1 differ from the ones originally given by Föhn (1987b) since his Eq. (5) still included the radius $r$ that also depends on $\alpha$. The value of $\alpha_{\max }$ for a typical avalanche slope of angle $38^{\circ}$ is $\alpha_{\max }=54.34^{\circ}$. Consequently, for this particular case of a $38^{\circ}$ slope angle, and for a typical skier load of $R=500 \mathrm{~N} \mathrm{~m}^{-1}$, the additional shear stress $\Delta \tau_{x z}$ (Eq. A7) simplifies to (Schweizer, 1997):

$\Delta \tau_{x z} \approx \frac{155}{h}$.

This equation has been used to compute $\Delta \tau_{x z}$ in Figs. 4 and 5 for the Boussinesq cases. 
Acknowledgements. We are grateful to the researchers of the University of Calgary for providing the data of 160 manual profiles including rutschblock tests. Johan Gaume was supported by the Swiss Government Excellence Scholarship and is grateful to the State Secretariat for Education, Research and Innovation SERI of the Swiss Government. We thank Karl Birkeland and Scott Thumlert for their valuable comments and remarks that helped us to improve our paper.

Edited by: T. Bogaard

Reviewed by: K. B. Birkeland and Scott Thumlert

\section{References}

Bartelt, P. and Lehning, M.: A physical SNOWPACK model for the Swiss avalanche warning: Part I: numerical model, Cold Reg. Sci. Technol., 35, 123-145, 2002.

Boussinesq, J.: Application des Potentials a l'Etude de l'Equilibre et du Mouvement des Solides Elastiques, Gauthier-Villars, Paris, France, 508 pp., 1885.

Bufler, H.: Theory of elasticity of a multilayered medium, J. Elasticity, 1, 125-143, 1971.

Burmister, D. M.: The general theory of stresses and displacements in layered systems. I, II, III, J. Appl. Phys., 16, 89-94, 1945.

Camponovo, C. and Schweizer, J.: Measurements on skier triggering, in: Proceedings International Snow Science Workshop, Banff, Alberta, Canada, 100-103, 1997.

Chiaia, B., Cornetti, P., and Frigo, B.: Triggering of dry snow slab avalanches: stress versus fracture mechanical approach, Cold Reg. Sci. Technol., 53, 170-178, 2008.

De Barros, T.: Deflection factor charts for two-and three-layer elastic systems, Highway Research Record, 83-108, 1966.

Fierz, C., Armstrong, R., Durand, Y., Etchevers, P., Greene, E., McClung, D., Nishimura, K., Satyawali, P., and Sokratov, S.: The International Classiffcation for Seasonal Snow on the Ground, UNESCO-International Hydrological Program, Technical Documents in Hydrology, 83, UNESCO, Paris, 90 pp., 2009.

Flamant, A.: Sur la répartition des pressions dans un solide rectangulaire chargé transversalement, CR Acad. Sci. Paris, 114, 14651468, 1892.

Föhn, P.: The rutschblock as a practical tool for slope stability evaluation, IAHS Publ., 162, 223-228, 1987a.

Föhn, P.: The stability index and various triggering mechanisms, IAHS Publ., 162, 195-214, 1987b.

Fretigny, C. and Chateauminois, A.: Solution for the elastic field in a layered medium under axisymmetric contact loading, J. Phys. D, 40, 5418-5426, 2007.

Gaume, J., Chambon, G., Eckert, N., and Naaim, M.: Influence of weak-layer heterogeneity on snow slab avalanche release: Application to the evaluation of avalanche release depths., J. Glaciol., 59, 423-437, 2013.

Gaume, J., Schweizer, J., van Herwijnen, A., Chambon, G., Reuter, B., Eckert, N., and Naaim, M.: Evaluation of slope stability with respect to snowpack spatial variability, J. Geophys. Res., 119, 1783-1789, doi:10.1002/2014JF003193, 2014.

Gaume, J., Chambon, G., Eckert, N., Naaim, M., and Schweizer, J.: Influence of weak layer heterogeneity and slab properties on slab tensile failure propensity and avalanche release area, The Cryosphere, 9, 795-804, doi:10.5194/tc-9-795-2015, 2015a.

Gaume, J., van Herwijnen, A., Chambon, G., Birkeland, K., and Schweizer, J.: Modeling of crack propagation in weak snowpack layers using the discrete element method, The Cryosphere, 9, 1915-1932, 2015b.

Geldsetzer, T. and Jamieson, J.: Estimating dry snow density from grain form and hand hardness, in: Proceedings International Snow Science Workshop, 1-6 October 2000, Big Sky, Montana, USA, 121-127, 2001.

Habermann, M., Schweizer, J., and Jamieson, B.: Influence of snowpack layering on human-triggered snow slab avalanche release, Cold Reg. Sci. Technol., 54, 176-182, 2008.

Heierli, J. and Zaiser, M.: Failure initiation in snow stratifications containing weak layers: Nucleation of whumpfs and slab avalanches, Cold Reg. Sci. Technol., 52, 385-400, 2007.

Heierli, J., Gumbsch, P., and Zaiser, M.: Anticrack nucleation as triggering mechanism for snow slab avalanches, Science, 321, 240-243, 2008.

Jamieson, B. and Johnston, C.: Refinements to the stability index for skier-triggered dry-slab avalanches, Ann. Glaciol., 26, 296-302, 1998.

Jamieson, J. and Johnston, C.: Evaluation of the shear frame test for weak snowpack layers, Ann. Glaciol., 32, 59-69, 2001.

Jamieson, B., Haegeli, P., and Gauthier, D.: Avalanche accidents in Canada, Canadian Avalanche Association, Revelstoke, BC, Canada, 1997-2007, 2010.

LaChapelle, E. R.: The fundamental processes in conventional avalanche forecasting, J. Glaciol., 26, 75-84, 1980.

Lehning, M., Bartelt, P., Brown, B., Russi, T., Stöckli, U., and Zimmerli, M.: SNOWPACK model calculations for avalanche warning based upon a new network of weather and snow stations, Cold Reg. Sci. Technol., 30, 145-157, 1999.

Lehning, M., Bartelt, P., Brown, B., and Fierz, C.: A physical SNOWPACK model for the Swiss Avalanche Warning Services. Part II: Snow Microstructure, Cold Reg. Sci. Technol., 35, 147167, 2002a.

Lehning, M., Bartelt, P., Brown, B., and Fierz, C.: A physical SNOWPACK model for the Swiss Avalanche Warning Services. Part III: Meteorological Boundary Conditions, Thin Layer Formation and Evaluation, Cold Reg. Sci. Technol., 35, 169-184, 2002b.

Lehning, M., Fierz, C., Brown, B., and Jamieson, B.: Modeling snow instability with the snow-cover model SNOWPACK, Ann. Glaciol., 38, 331-338, 2004.

McCartney, J., Brady, R., Wood, C., and Curry, B.: Evaluation of Geosynthetic-Reinforced Flexible Pavements using Static Plate Load Tests, unpublished data, 2013.

McClung, D.: Shear fracture precipitated by strain softening as a mechanism of dry slab avalanche release, J. Geophys. Res., 84, 3519-3526, 1979.

McClung, D.: The elements of applied avalanche forecasting, Part II: the physical issues and the rules of applied avalanche forecasting, Nat. Hazards, 26, 131-146, 2002.

McClung, D. and Schweizer, J.: Skier triggering, snow temperatures and the stability index for dry-slab avalanche initiation, J. Glaciol., 45, 190-200, 1999.

Monti, F., Gaume, J., and Schweizer, J.: Deriving snow stability information from simulated snow cover stratigraphy, in: 2014 In- 
ternational Snow Science Workshop, edited by: Haegeli, P., Banff, Alberta, 465-469, 2014a.

Monti, F., Schweizer, J., and Fierz, C.: Hardness estimation and weak layer detection in simulated snow stratigraphy, Cold Reg. Sci. Technol., 103, 82-90, 2014b.

Palmer, L. A. and Barber, E. S.: Soil displacement under a circular loaded area, Proceedings of the 20th Annual Meeting of the Highway Research Board, 3-6 December 1940, Washington, D.C., 279-286, 1941.

Reiweger, I., Gaume, J., and Schweizer, J.: A new mixed-mode failure criterion for weak snowpack layers, Geophys. Res. Lett., 42, 1427-1432, doi:10.1002/2014GL062780, 2015.

Reuter, B., Schweizer, J., and van Herwijnen, A.: A process-based approach to estimate point snow instability, The Cryosphere, 9, 837-847, 2015.

Schweizer, J.: The influence of the layered character of snow cover on the triggering of slab avalanches, Ann. Glaciol., 18, 193-193, 1993.

Schweizer, J.: Contribution on the skier stability index, Internal report, Swiss Federal Institute for Snow and Avalanche Research, Davos, Switzerland, 1997.

Schweizer, J. and Camponovo, C.: The skier's zone of influence in triggering slab avalanches, Ann. Glaciol., 32, 314-320, 2001.

Schweizer, J. and Jamieson, J.: Snow cover properties for skier triggering of avalanches, Cold Reg. Sci. Technol., 33, 207-221, 2001.

Schweizer, J. and Jamieson, J. B.: Snowpack properties for snow profile analysis, Cold Reg. Sci. Technol., 37, 233-241, 2003.

Schweizer, J. and Lütschg, M.: Characteristics of human-triggered avalanches, Cold Reg. Sci. Technol., 33, 147-162, 2001.

Schweizer, J. and Wiesinger, T.: Snow profile interpretation for stability evaluation, Cold Reg. Sci. Technol., 33, 179-188, doi:10.1016/S0165-232X(01)00036-2, 2001.

Schweizer, J., Schneebeli, M., Fierz, C., and Föhn, P. M.: Snow mechanics and avalanche formation: Field experiments on the dynamic response of the snow cover, Surv. Geophys., 16, 621633, 1995.

Schweizer, J., Jamieson, J. B., and Schneebeli, M.: Snow avalanche formation, Rev. Geophys., 41, 1016, doi:10.1029/2002RG000123, 2003a.
Schweizer, J., Kronholm, K., and Wiesinger, T.: Verification of regional snowpack stability and avalanche danger, Cold Reg. Sci. Technol., 37, 277-288, 2003b.

Schweizer, J., Bellaire, S., Fierz, C., Lehning, M., and Pielmeier, C.: Evaluating and improving the stability predictions of the snow cover model SNOWPACK, Cold Reg. Sci. Technol., 46, 52-59, 2006.

Schweizer, J., Kronholm, K., Jamieson, J., and Birkeland, K.: Review of spatial variability of snowpack properties and its importance for avalanche formation, Cold Reg. Sci. Technol., 51, 253272, 2008a.

Schweizer, J., McCammon, I., and Jamieson, J. B.: Snowpack observations and fracture concepts for skier-triggering of dry-snow slab avalanches, Cold Reg. Sci. Technol., 51, 112-121, $2008 \mathrm{~b}$.

Schweizer, J., van Herwijnen, A., and Reuter, B.: Measurements of weak layer fracture energy, Cold Reg. Sci. Technol., 69, 139144, 2011.

Sigrist, C.: Measurements of fracture mechanical properties of snow and application to dry snow slab avalanche release, $\mathrm{PhD}$ thesis, ETH Zürich, Zürich, 2006.

Sigrist, C. and Schweizer, J.: Critical energy release rates of weak snowpack layers determined in field experiments, Geophys. Res. Lett., 34, L03502, doi:10.1029/2006GL028576, 2007.

Smith, F., Sommerfeld, R., and Bailey, R.: Finite element stress analysis of avalanche snowpacks, J. Glaciol, 10, 401-405, 1971.

Thumlert, S. and Jamieson, B.: Stress measurements in the snow cover below localized dynamic loads, Cold Reg. Sci. Technol., 106, 28-35, 2014.

Vakili, J.: A simplified method for evaluation of pavement layers moduli using surface deflection data, Proceedings of the 12th International Conference of International Association for Computer Methods and Advances in Geomechanics (IACMAG), 16 October 2008, Goa, India, 4314-4319, 2008.

van Herwijnen, A. and Jamieson, B.: Snowpack properties associated with fracture initiation and propagation resulting in skiertriggered dry snow slab avalanches, Cold Reg. Sci. Technol., 50, 13-22, 2007. 